\title{
The Malabsorption Syndrome versus Celiac Disease: A Diagnostic Reappraisal
}

\author{
Andrej Beseda, Marián Bencat, Lubica Korinkova, Janka Papanová, Julius Rajcani* \\ Pathology, Diagnostic center, Alpha medical Ltd, Martin, Slovakia \\ *Corresponding author: rajcani.julius@alphamedical.sk
}

Received August 28, 2015; Revised September 15, 2015; Accepted September 28, 2015

\begin{abstract}
The most frequent cause of malabsorption syndrome (MAS) in developed countries is the celiac disease (CD). There are two possible approaches for exact diagnostic of this disorder: in case of full blown clinical symptoms the golden standard is duodenal biopsy. When it shows classical mucosa lesions (Marsh type 3 mucosa atrophy of various grades), the diagnosis of $\mathrm{CD}$ is confirmed. However, if intraepithelial lymphocyte infiltration (IEL) and/or hyperplastic crypts can be seen in the absence of mucosa atrophy (Marsh type 1 and/or 2 lesions) only, it is reasonable to examine the serologic markers. The most frequent enzyme linked immunosorbent assay (ELISA) tests are: detection of tissue transglutaminase 2 antibody (anti-tTGase 2, especially of IgA class) and the deamidated gliadin peptide antibody (anti-DGP) assay. A simpler serological test, useful for screening, is the detection of antiendomysium antibody (AEmA) by indirect fluorescent antibody (IFA) in monkey intestine or esophagus sections. This is reasonable to combine with the microdot test for anti-gliadin antibody (AGA), especially by using the endomysium/gliadin mosaic kit (Euroimmun). Taken together, at least three serological markers (anti-tTGase 2, antiDGP and AGA) are highly specific for CD; their detection first (i.e. prior to duodenal biopsy) is recommended in children as well as in adults showing atypical, silent and or latent forms of CD. In both of them, serology represents a reliable non-invasive approach, which allows precise diagnosis with a probability of nearly $90 \%$. Another advantage of the non-invasive serological technic is that it can be easily repeated when following the outcome of gluten-free diet (GFD). Nevertheless, duodenal biopsy should be performed in any case, if the serology does not correlate with clinical symptoms. In such patients as well as in those revealing positive serology but negative and/or non-specific histology, immunogenetic typing should be performed in order to assess the expression of DQ2 [DQA*0501-DQB*0201] or DQ8 [DQA*0301-DQB1*0302] haplotypes of the human leukocyte antigen (HLA) class II region critical for the development of CD.
\end{abstract}

Keywords: malabsorption syndrome, celiac disease, gluten sensitivity, diagnostic, duodenal biopsy, serological markers

Cite This Article: Andrej Beseda, Marián Bencat, Lubica Korinkova, Janka Papanová, and Julius Rajcani, “The Malabsortion Syndrome versus Celiac Disease: A Diagnostic Reappraisal.” International Journal of Celiac Disease, vol. 3, no. 4 (2015): 118-131. doi: 10.12691/ijcd-3-4-5.

\section{Introduction}

Malabsortion syndrome (MAS) is a clinical entity [1] with variable signs and symptoms associated with disturbed resorption of nutrients. As shown in Table 1, in MAS the impaired resorption of lipids (especially triglycerids) prevails, followed by disturbed ingestion of amino acids, saccharides (intolerance for galactose and glucose in children), minerals and certain vitamins (cobolamin/vitamin B12 and folate). There are two basic forms of MAS (Table 2): primary form (which develops due to primary damage of the epithelium cells lining the intestinal villi and crypts) and the secondary form (when clinical symptoms related to mucosal damage occur due to external influences such as infection, surgery and/or in response to drugs and chemicals). In the past, MAS occurring in tropical countries (such as India) has been referred to as tropical sprue, but recently the term tropical malabsorption (TM) is preferred. TM is mainly of infectious origin, most probably associated with giardiasis, strongiloidiasis and/or intestinal tuberculosis [2,3], whereas the MAS occurring in developed countries is frequently related to CD. Thus, the etiology of TM in tropical areas usually differs from that of non-infective CD occurring in countries with temperate climate. This notion is supported by the existence of the epidemic form TM reported in Pakistan [4], Thailand [5] and/or in other South-East Asia regions including Malaysia [6]. The emergence of TM in the subtropical Caribbean countries such as Puerto Rico, was probably related to poor sanitary conditions, i.e. just indirectly associated with the climate itself $[7,8]$.

In recent years, the frequency of infective $\mathrm{TM}$ in developing countries has declined, supporting the secondary role of tropical climate and stressing the importance of sanitary conditions and/or of the increasing use of antibiotics and related drugs. Nevertheless, no clear 
evidence exists in favor of this statement. It should be kept in mind that some overlap may exist between the genuine (primary) intestinal lesions associated with $\mathrm{CD}$ and the mild of forms of infective TM. Such overlap condition is referred to as small intestinal bacterial overgrowth (SIBO). The SIBO syndrome has been associated with the irritable bowel syndrome (IBS), a common condition in countries with temperate climate $[9,10]$. Symptoms of SIBO include abdominal pain, bloating, flatulence, and diarrhea, similar to those observed in patients with IBS. The clinical diagnosis of IBS is based on a combination of similar symptoms. It is possible that some patients may be misdiagnosed as IBS, particularly if no specific diagnostic tests are performed. The SIBO represents an increased and/or abnormal number of bacteria in the small intestine. The bacterial nature of SIBO can be proven by the Hydrogen breath testing $\left(\mathrm{H}_{2} \mathrm{BT}\right)$ either with glucose or lactulose. An abnormally high bacterial count $\left(\geq 10^{5}\right.$ colony-forming units/ml) in the proximal small intestine may approximate the amounts of bacteria normally found in the colon. More precisely, the stomach and proximal small bowel (including duodenum) in adults normally contain relatively small numbers of bacteria. The bacterial concentration in the gut increases from $10^{-4}$ colony forming units per $\mathrm{ml}(\mathrm{cfu} / \mathrm{ml})$ in the duodenum and the jejunum up to $10^{-5} \mathrm{cfu} / \mathrm{ml}$ in the proximal ileum; however, it easily reaches $10^{-8} \mathrm{cfu} / \mathrm{ml}$ in the terminal ileum and $10^{10-12} \mathrm{cfu} / \mathrm{ml}$ in the caecum $[11,12]$. The flora in the upper small bowel consists mainly of Gram-positive rods; the numbers of Gram negatives are low and the anaerobes, so much frequent in colon, are very rare [13]. In the past, SIBO had been interpreted acting in accord with other predisposing conditions, such as impaired intestinal motility or failure of the gastric-acid barrier $[14,15]$. Taking advantage of the glucose hydrogen breath test (GHBT) and/or the ${ }^{14} \mathrm{C}$-xylose breath tests (both considered for fairly reliable), there was shown that in IRB only mildly increased bacterial counts occur within the small-bowel. Therefore, the potent motility alterations in IBS cannot be predicted by increased small-bowel bacterial flora, rather the opposite may be the case [16]. Thus, the association between SIBO and IBS remains very uncertain [17], even when SIBO related IBS patients would respond to antibiotic treatment by temporary improvement. The SIBO patients, therefore, should be examined for serologic markers, especially when the clinical signs are indicative for CD in order to exclude the latter $[18,19]$.

Table 1. Clinical symptoms in MAS and recommended laboratory tests

\begin{tabular}{|l|l|}
\hline Symptom, clinical sign & Laboratory test \\
\hline Steatorrhea (pale stool in abundance) & Analysis for lipids in the stool, lipemia in blood (triglycerids) \\
\hline Chronic diarrhea & \\
\hline Enlarged belly & \\
\hline Anorexia & \\
\hline Weight lost & \\
\hline Dehydration & \\
\hline Hypotension & $\begin{array}{l}\text { Lactose tolerance, D-xylose tolerance, Schilling's test } \\
\text { Duodenal biopsy for histology and/or immunohistochemistry (CD3 lymphocytes) } \\
\text { Serology: determination of antibodies to gluten (AGA) and/or of autoantibodies such ase } \\
\text { anti-tTGase2 and anti-DGP. } \\
\text { Muscle wasting }\end{array}$ \\
$\begin{array}{l}\text { Fatty liver } \\
\text { Anemia }\end{array}$ & \\
$\begin{array}{l}\text { Hypoalbuminemia } \\
\text { Apathy and failure } \\
\text { Hair changes: the flag sign }\end{array}$ & \\
\hline
\end{tabular}

Table 2. The etiology of malabsorption syndrome (MAS)

\begin{tabular}{|l|l|l|l|}
\hline \multicolumn{2}{|c|}{ Primary MAS } & & Secondary MAS \\
\hline Celiac disease & Gluten sensitivity on genetic basis* & Digestion defects & $\begin{array}{l}\text { Impaired hepatobiliary function } \\
\text { Impaired gastric function }\end{array}$ \\
\hline & Rare sensitivity to other prolamins & $\begin{array}{l}\text { SIBO (small intestine bacterial overgrowth) } \\
\text { Parasites } \\
\text { Post-surgery (intestine removal) } \\
\text { Endocrine disorders } \\
\text { Drugs, chemical poisoning, irradiation }\end{array}$ \\
\hline Selective primary MAS & Post-infection state & Resorption defects & IBS (irritable bowel syndrome) \\
\hline & Amino acid metabolic disturbance & Malnutrition & Intestinal motility disturbances \\
\hline & MAS for disaccharides & & \\
\hline
\end{tabular}

*HLA II haplotypes DQ2 and DQ8 preferentially develop CD.

As described below, the genuine CD is characterized by typical small-intestinal mucosa lesions mainly occurring in genetically susceptible individuals (HLA II haplotypes DQ2 and DQ8), who respond by MAS to the dietary ingestion of wheat gluten (and/or similar prolamins) present in barley and rye [reviewed by Kagnoff, [20]]. In addition to villous atrophy of intestinal mucosa, higher platelet counts were found as a relevant diagnostic sign [21]. On other hand, TM is an infectious disease, which may start acutely by an episode of gastrointestinal infection. It may be partially treated with antibiotics before reaching a regional healthcare center. Since TM is 
a relatively serious disease, which cannot be treated by gluten-free diet (GFD), it must not be mistaken for CD. The sudden emergence of TM in developed countries with a high standard of hygiene is possible, especially among tourists who have returned from tropical areas such as South Asia [22]. In presented review, we briefly reconsider the classical signs of $\mathrm{CD}$ as well as the lesions seen in duodenal biopsy, along with the diagnostic significance of recently described serologic markers, which, under careful precautions, can be regarded for highly specific. The serologic markers are of special importance in children, in which they have been regarded for a superior diagnostic tool $[23,24]$. On other hand, duodenal biopsy still remains the golden diagnostic standard in any case (even in children), when clinical signs do not correlate with positive serologic tests [25].

\section{Histological Findings in $\mathrm{CD}$ and Related Diseases}

From the intestine lumen, nutrients are absorbed by the tall columnar epithelium cells (at least $30 \mu \mathrm{m}$ high), also called enterocytes, lining the finger-like extensions of mucosa. The absorption surface at apical end of each enterocyte is substantially increased by the brush border (as described by light microscopy), which is represented by approximately $1 \mu \mathrm{m}$ long microvilli clearly seen by electron microscopy. The villi are composed of loose connective tissue, which contains capillary and lymphatic vessel loops and a few smooth muscle cells. The connective belonging to lamina propria on one hand extends to above mentioned villi and on other hand, it surrounds the simple tubular intestinal glands, the so called crypts of Lieberkuehn, which are inverted structures increasing the inner space of intestine. In addition to absorptive enterocytes, the villi are covered by goblet cells, by antigen presenting microfold cells ( $\mathrm{M}$ cells), by regenerative stem cells, by exocrine Paneth cells and, at last but not least, by the so called enteroendocrine cells, producing paracrine hormones such as somatostatin, serotonin, gastrin and others. The above mentioned exocrine and entero-endocrine cells as well as the majority of stem cells are mainly located in the wall of tubular crypts [26]. The lateral membranes of cylindric epithelium cells are interconnected by intercellular desomosomes and gap junctions equipped with adherent as well as occludent zonules. These intercellular structures contain special junctional proteins such as occludin, claudin 3, E-cadherin and the zona occludens protein. The expression of junction proteins, when compared to non-celiac controls, was found decreased already at the early stage of CD. At early infiltrative phase of CD (referred to as Marsh type 1/stage I/grade A lesion), the expression of junction proteins correlates negatively with the increased number of IEL. The expression of claudin 3 shows a negative correlation with the diarrhea score. These findings indicate that the integrity of intestinal epithelium might be disrupted already before progression to the full blown classical Marsh type 3 CD lesion [27].

Table 3. Overview of histological lesions of duodenal mucosa in CD (modified from Marsh classification) ${ }^{1}$

\begin{tabular}{|c|c|c|l|l|l|l|l|}
\hline Type & Stage & Grade & Epithelium cells (EpC) & Villi $^{3}$ & Crypts & IEL/EpC & Description (Figure) \\
\hline 0 & 0 & 0 & Normal size and height & Unaltered & Unaltered & $<40 / 100^{1}$ & $\begin{array}{l}\text { Preinfiltrative mucosa (Figure 2A, Figure } \\
\text { 3A, Figure 3B)* }\end{array}$ \\
\hline 1 & I & A & Normal size and height & Unaltered & Unaltered & $>40 / 100$ & $\begin{array}{l}\text { Infiltrative lesion of the epithelium (Figure } \\
\text { 3C, Figure 4A) }\end{array}$ \\
\hline 2 & II & A & Normal size and height & Unaltered & Proliferation & $>40 / 100$ & Crypt hyperplasia, hyperplastic mucosa \\
\hline 3a & IIIA & B1 & Height of EpC reduced & Partial atrophy & Proliferation & $>40 / 100$ & $\begin{array}{l}\text { Classical lesion (Figure 2B, Figure 2C, } \\
\text { Figure 3E, Figure 3F)** }\end{array}$ \\
\hline 3b & IIIB & B1 & Height of EpC reduced & Subtotal atrophy & Proliferation & $>40 / 100$ & $\begin{array}{l}\text { Classical lesion (Figure 2D, Figure 3D, } \\
\text { Figure 4B)** }\end{array}$ \\
\hline 3c & IIIC & B2 & $\begin{array}{l}\text { Cuboidal EpC (not } \\
\text { differentiated) }\end{array}$ & Subtotal atrophy & Proliferation & $>40 / 100$ & $\begin{array}{l}\text { Progressed lesion, lymphocyte infiltration in } \\
\text { lamina propria (Figure 4C, Figure 4D) }\end{array}$ \\
\hline 3c & IV ${ }^{4}$ & B2 & $\begin{array}{l}\text { Cuboidal EpC (not } \\
\text { differentiated, no brush } \\
\text { border) }\end{array}$ & Total atrophy ${ }^{4}$ & hypoplastic & $<40 / 100$ & $\begin{array}{l}\text { End stage lesion (massive lymphocyte } \\
\text { infiltration in lamina propria, but no IEL), } \\
\text { hypoplastic crypts and total absence of villi. }\end{array}$ \\
\hline
\end{tabular}

* Serologic markers might be positive in about $5 \%$ of cases with HLA DQ2 and/or HLA DQ8 genotypes (latent form of CD)

** Referred to as destructive (Marsh, 1992)

***Lymphocyte infiltration in lamina propria

${ }^{1}$ the original borderline value has been claimed 25 IEL /100 EpC (Marsh and Crove, 1995)

${ }^{2}$ schematic view of the lesion dynamics shown on Figure 1A; ${ }^{3}$ schematic view of lesion dynamics shown on Figure 1B

${ }^{4}$ some authors do not accept this category suggesting its cancelling.

The early lesions at the infiltrative phase of CD appear first on surface epithelium (Figure 1A), where the increased number of IEL dominates; the infiltrate consists mainly of $\mathrm{CD}^{\text {posit }} \mathrm{T}$ - lymphocytes [28]. Marsh and Crowe [29] elaborated the histological classification of duodenal mucosa pattern in $\mathrm{CD}$, introducing the recent three-degree grading of mucosa lesions, still used worldwide with small modifications. In type 1 lesions, the IEL count is increased, but the villous atrophy is absent. Precise counts of the IEL/enterocyte ratio as performed by several authors were based on the CD3 marker stain [30,31,32]. The borderline for pathological IEL has been determined as minimum at $25 \mathrm{CD}^{+}$T-lymhocytes per 100 enterocytes, while a range from 25 to $4 \mathrm{CD}^{+}$lymphocytes per 100 enterocytes may be accepted for basic value (Table 3). Even though confirming the improved precision of $\mathrm{CD}^{\text {posit }} \mathrm{T}$ lymphocyte counts in duodenal biopsy sections, some authors stress that the borderline IEL criterion alone may not be satisfactory for the diagnosis of the early stage of gluten-sensitive enteropathy [33]. The finding of increased IEL counts in the absence of other mucosa lesions classified as Marsh type 1, is not specific for CD. Increased IELs counts in the small bowel mucosa have been found also in TM, in food protein intolerance (enteropathy associated with substances other than gluten), in Helicobacter pylori associated gastritis and/or in peptic 
duodenitis, not excluding some parasitic and/or viral infections (Table 2); similar accumulation of $\mathrm{CD}^{\text {posit }} \mathrm{T}$ cells appears during the development of intestinal lymphoma [34]. In the meantime, additional diagnostic approaches beyond the conventional histology of early Marsh type 1 lesion, have been introduced to elucidate the diagnosis of CD [35,36]. The recent ESPGHAN guidelines for the diagnosis of early $\mathrm{CD}$ lesions encompasses both, a high $\mathrm{CD}^{\text {posit }} \mathrm{T}$ - lymphocyte (IEL) count as well as the presence of deposits in the lamina propria consisting of IgA class antibody and tTGase 2 antigen. The latter finding increases the likelihood of CD development [37] along with the positive serum antibody markers. Asymptomatic patients are typically diagnosed through serologic screening, which can be done first if the individual has atypical symptoms and/or if he is a firstdegree relative to a patient with CD [38]. However, the diagnosis of CD requires duodenal biopsy, when the adult patient is on GFD due to long lasting positive serology.

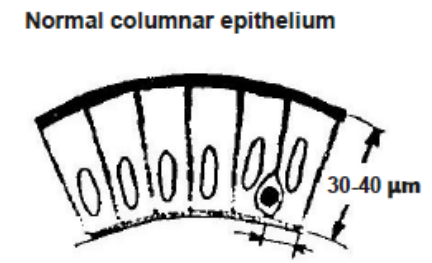

Notes: finger and/or leaf shaped villi

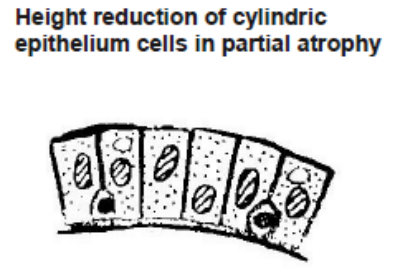

irregular nuclei with disturbed polarity, basophilic cytoplasm with vacuolization, brush border very thin, irregular or missing
Cuboidal columnar epithelium
cells in subtotal atrophy

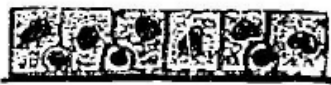

round shaped hyperchromatous nuclei, more basophilic cytoplasm no or very thin brush border

Figure 1A. Schematic representation of morphological changes of enterocytes in CD. Enterocytes become lower, they show basophilic cytoplasm and irregular nuclei. The brush border is thin and later on disappears. In subtotal atrophy the enterocytes are non-differentiated cuboidal cells with round shaped small nuclei and basophilic cytoplasm

A considerable of population of $\mathrm{CD}^{\text {posit }} \mathrm{T}$ cells has a different $\mathrm{T}$ cell receptor (TCR), namely that composed of $\gamma \delta$ subunits, instead of the usual $\alpha \beta$ subunits. In progressed $\mathrm{CD}$, characterized by mucosal atrophy, the increase of $\mathrm{CD}^{\text {plus }} / \mathrm{TCR} \gamma \delta$ lymphocytes and concomitant decrease of CD3 ${ }^{\text {minus }}$ IEL counts was described by flow cytometry of duodenal biopsy eluates [39]. For such investigations, the duodenal biopsy sample was immediately processed with a suitable buffer (HBSS). To prepare a relatively pure IEL suspension, the total villous epithelium fraction must have been removed along with at least a part of crypt epithelium cells. Immunohistochemical analysis was done using directly labeled monoclonal antibodies to define the different IEL subsets. The following sera were used by above mentioned authors: 1. anti-CD45-APC /clone 2D1; 2. anti CD3-PerCP/clone SK7, 3. anti CD103-FITC/clone Ber-ACT8 and 3. anti-TCR $\gamma \delta-P E / c l o n e ~ 11 F 2$. Such thorough analysis cannot be accomplished at routine diagnostic work. We still believe that consequent use of the CD3 marker staining at histological examination of duodenal tissue sections, considerably improves the evaluation of IEL counts. This statement is evident when looking at given examples of duodenal biopsy samples (Figure 2 and Figure 3). Fully convincing histological diagnostic signs are inflammatory infiltration, increased IEL counts ( $>25 / 100$ ), villous atrophy of at least mild grade with an uneven brush border (Figure 1A, Marsh type 3a lesion). In addition, the critical leukocyte antigen (HLA) haplotypes DQ2 and/or DQ8 should be found by immunogenotyping. The importance of serologic markers in the case of uncertain histological findings as well as in the monitoring of therapy (especially when following the effect of GFD), comes from the high specificity and noninvasive nature of blood sampling. The key role of serology is also related to the fact that persistent IEL may still remain in a proportion of CD patients, who have undergone a long-term strict GFD [40,41]. In this connection, the so called refractory form of CD has been described. The seronegative form of CD (SNCD) is also known, being defined by negative anti-tTGase 2 antibodies in the presence of a positive duodenal biopsy (histological lesions at least of Marsh type 3a). SNCD is characterized by mucosal deposits of above mentioned immunocomplexes containing tTGase 2 antigen and anti-tTGase 2 class IgA antibody. The deposits in question may counteract the passage of anti-tTGase antibody into the bloodstream explaining the continuing seronegativity [42]. Another reason for seronegativity may be the incomplete maturation of plasma cells with consequent failure of antibody production. This condition often characterizes immunoglobulin deficiencies, and indeed, SNCD is common in subjects with this defect (see below).

Further histological criterion for early CD lesions is the elongation of crypts. In the hyperplasia phase (Marsh type 2 ), the crypt/villum length ratio is of $1: 2$ or $1: 3$ (Figure $1 \mathrm{~B}$ ), while the conventional (normal) ratio uses to be 1:5 (Table 4). The elongation of crypts is related to the proliferation of regenerative stem cells, which prevail within the crypts. Their activated division can be assessed using the Ki-67 proliferation marker staining better than looking for mitoses in hematoxylin and erythrosine sections. The hyperplasia of crypts along with a given stage of villous atrophy (usually graded partial or subtotal) and enterocyte alterations (Figure 1A) are the dominant features of Marsh type 3 lesions. As presented on Figure 4, the differences between lesion subtypes when compared to unchanged (and/or regular sized) villous structures can be easily recognized. These changes comprise a dynamically interrelated series of events, culminating in a final and severe flat-destructive lesion. In contrast to about $25 \%$ gluten-sensitive enteropathies, no case of complete villous blunting (Marsh type 3c) has been reported in TM [22]. As shown on Figure 1B and mentioned in Table 4, in TM the subtotal atrophy of villi is not associated with hyperplasia of crypts. The latter rather show a hypoplastic pattern, so that the $\mathrm{VH}$ : $\mathrm{CH}$ ratio remains unchanged. TM is also characterized by incomplete duodenal villous blunting which never shows a flat mucosa. Furthermore, 
there is some involvement of terminal ileum along with a marked inflammation of the lamina propria in that region.
The anti-tTGase 2 antibody, so typical for CD (with the exception of rare SNCD cases) is not found in TM.
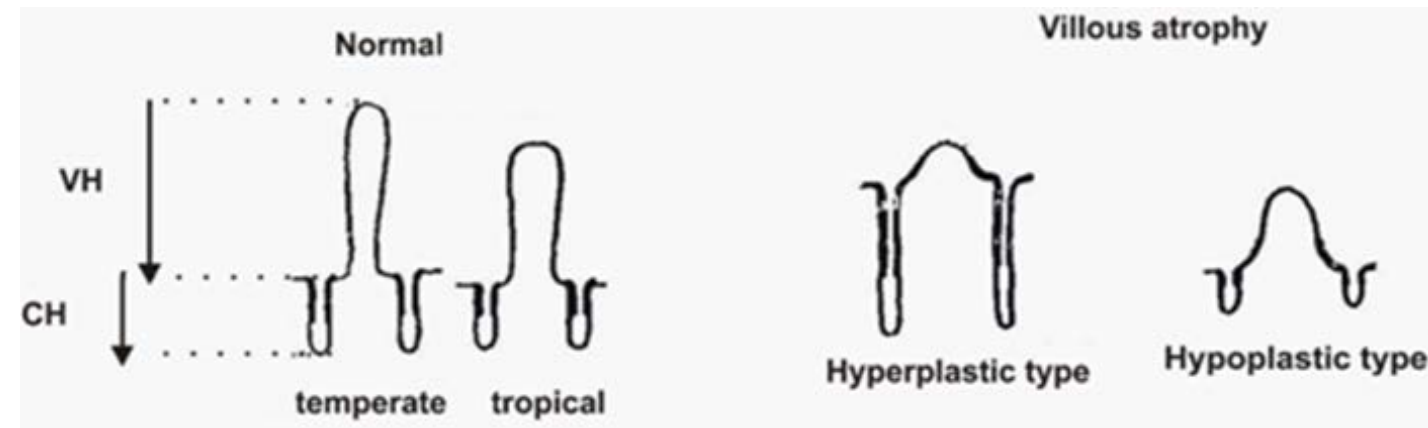

Figure 1B. Schematic representation of the villi and crypts of intestinal mucosa in CD. For explanation see Table 4 (VH: villous height, CH: crypt height)

Table 4. Explanations to the legend of the Figure 1B

\begin{tabular}{|c|c|c|c|c|}
\hline & \multirow{2}{*}{$\begin{array}{l}\text { Normal } \\
\text { temperate* }\end{array}$} & \multirow{2}{*}{$\begin{array}{l}\text { Normal } \\
\text { tropical* }\end{array}$} & \multicolumn{2}{|c|}{ Villous atrophy } \\
\hline & & & hyperplastic type & hypoplastic type \\
\hline Height of villi $(\mathrm{HV})^{1}$ & 413 & 311 & & \\
\hline Height of crypts $(\mathrm{HC})^{2}$ & 169 & 139 & & \\
\hline $\mathrm{HC}$ to $\mathrm{HV}$ ratio & 0.43 & 0.45 & & \\
\hline Total height HC + HV & 582 & 438 & & \\
\hline Mitotic index** & 0.63 & 0.34 & & \\
\hline Villous epithelium & & & $\begin{array}{l}\text { Enterocytes abnormal, } \\
\text { IEL increased }\end{array}$ & $\begin{array}{l}\text { Enterocytes normal, } \\
\text { occasional megalocytes }\end{array}$ \\
\hline Crypt epithelium & & & $\begin{array}{l}\text { Enteroblasts normal } \\
\text { Paneth cells decreased } \\
\text { Argentaffine cells increased }\end{array}$ & Atypical or megalocytic enteroblasts \\
\hline Mechanisms & & & Life span of enterocytes shortened & Impaired enterocyte production \\
\hline
\end{tabular}

${ }^{1}$ (less than 300 micrometers)

${ }^{2}$ (over 0.6)

*data in micrometers

** the proportion of mitotic cells per 100 columnar cells.
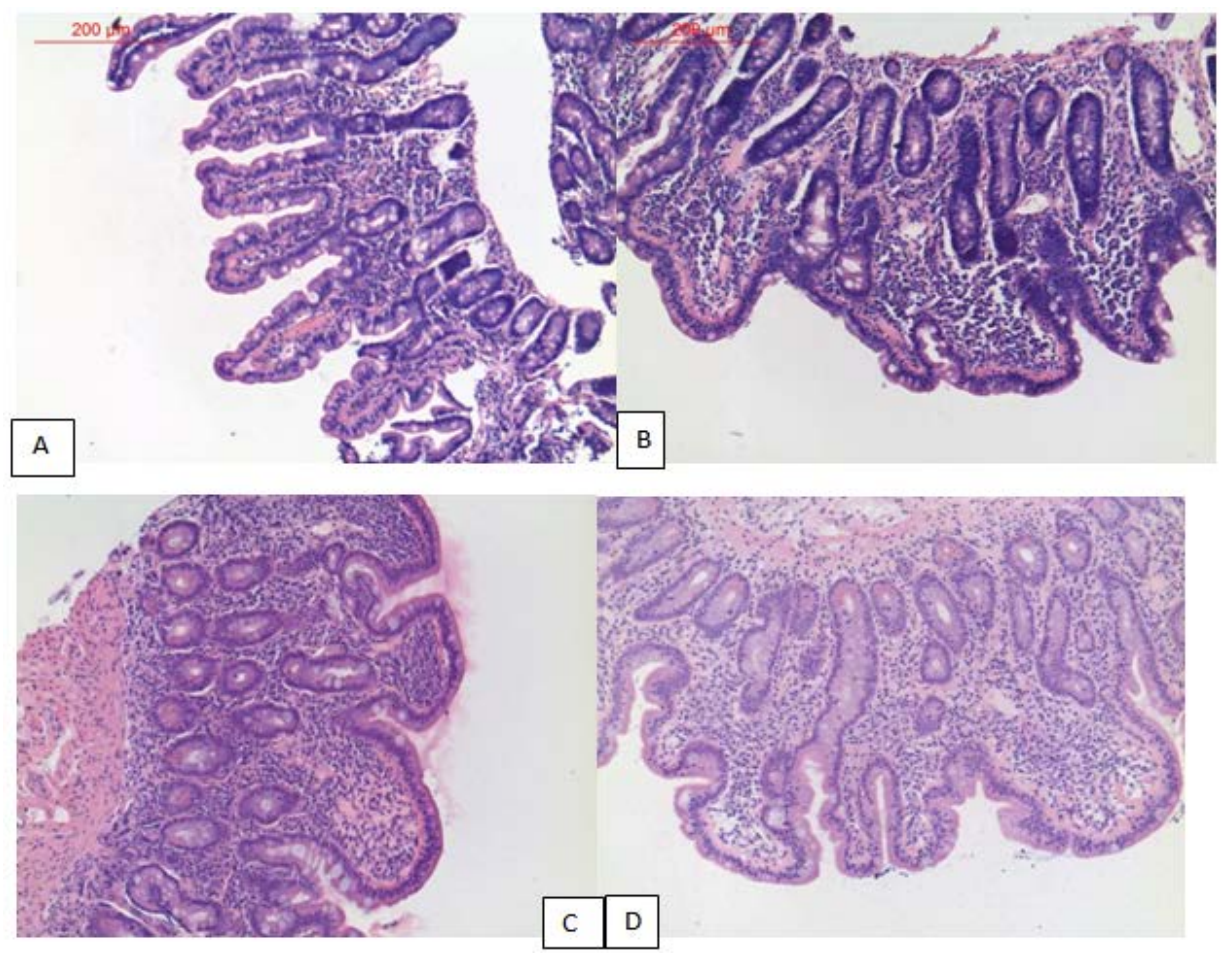

Figure 2. Classical CD lesions seen in duodenal biopsy by HE stain (in B, C and D) as compared to normal duodenal mucosa (A)

Figure 2A (above in the left): the normal duodenal mucosa. Figure 2B (above in the right) and Figure 2C (below in the left): both examples show partial atrophy of villi, hyperplastic crypts and reduced height of enterocytes (Marsh type 3a, stage III, grade B1). Figure 2D (below in the right): shows subtotal atrophy of villi, hyperplasia of crypts and reduced height of enterocytes (Marsh type 3b, stage III, grade B1). Note: for precise IEL counts the CD3 marker staining should be performed. 

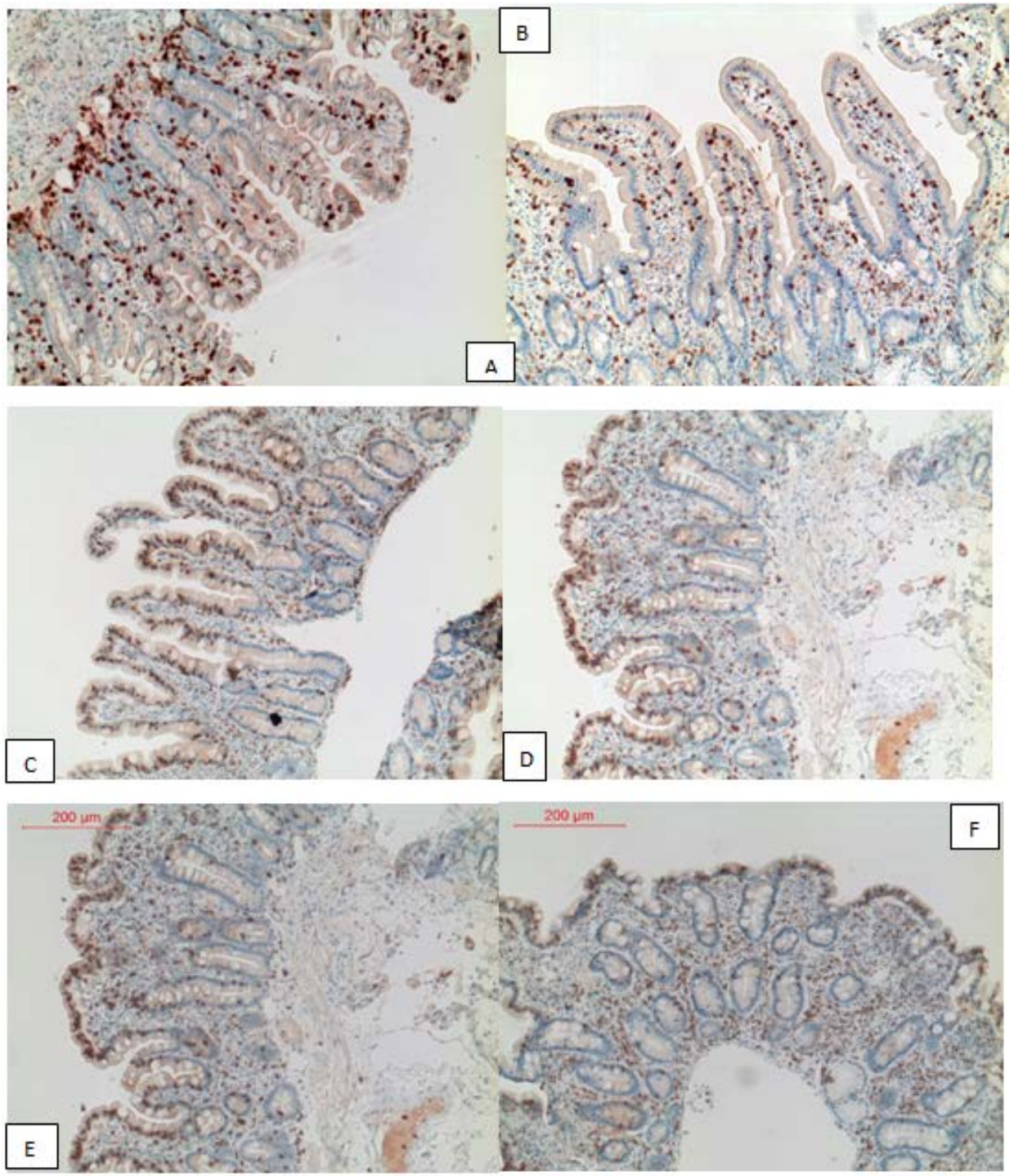

Figure 3. Classical CD lesions in duodenal biopsy: CD3 staining of T lymphocytes (from C to F) as compared to normal duodenal mucosa (at A and B)

Figure 3A and Figure 3B. Normal duodenal mucosa; the villi are lined by enterocytes and goblet cells (in the left); the crypts can be seen in transversal section (in the right). The intraepithelial lymphocytes (IEL) in between enterocytes were stained for the CD3 marker (using anti-CD3 monoclonal antibody). Figure 3C (in the left, middle row) shows an infiltrative lesion characterized by increased number of IEL (Marsh type 1, stage I, grade A,). Figure 3D (in the right, middle row): shows a classical lesion with subtotal atrophy of villi, which are lined by enterocytes of reduced height; many IEL can be seen (Marsh type 3b, stage IIIB, grade B1). Figure 3E (in the left below): partial atrophy of villi, reduced height of enterocytes and slight hyperplasia of crypts (Marsh type 3a, grade B1, stage IIIA). Figure 3F (in the right below): partial atrophy of villi with slight hyperplasia of crypts (Marsh 3a grade B1, stage IIIA). In both classical lesions the number of IEL is abundant; note the difference between Figure 3C (no atrophy of villi, Marsh type 1) and Figure 3E and 3F (Marsh type 3a) as well as Figure 3D (Marsh type 3b).

Taken together, in CD four possible diagnostic patterns are recognized: (1) The typical most commonly diagnosed form, characterized by full blown gastrointestinal signs (intestinal malabsorption), developed villous atrophy along with other classical histological lesions (histology plus). (2) Atypical or extra intestinal form, where the gastrointestinal symptoms are minimal or even absent, but if examined by duodenal biopsy, a fully developed villous atrophy can be seen along with the serological manifestations (serology plus, histology plus, clinical signs minimal or atypical). Since the onset of their disease, these patients may not be considered for having CD, at least not from gastrointestinal point of view. A large number of them goes undiagnosed, or becomes examined for other reasons such as iron deficiency, osteoporosis, short stature or infertility. (3) Silent form of CD, which represents a group of patients who have no clinical symptoms, but villous atrophy can be discovered during endoscopy undertaken for another reason. If tested, the
CD related autoantibodies can be detected by serology. (4) In latent from, the individuals possessing genetic susceptibility (DQ2 or DQ8 HLA II haplotypes), for example the relatives of $\mathrm{CD}$ patients, will subsequently develop CD despite of the currently normal intestinal mucosa, especially when remaining on a standard (glutencontaining) diet. Another latent CD patients show positive autoimmune serology, but still reveal normal mucosa by histology (representing the serology positive, but histology negative variant) or show the Marsh type 1 infiltrative lesion, which is not significant for CD [43]. These latter patients are very difficult to identify and even more questionable is their classification among those really having $\mathrm{CD}$. Some of these patients may reveal a history of previous CD positive histology, who responded to GFD by retaining a normal mucosal histology, while other just reacted by keeping an increased IEL manifestation, which itself is not specific so that any diagnostic decision becomes difficult. The latter patients 
fulfill the category of the refractory form of CD, represented by patients with positive serology along with the minimal Marsh type 1 histology, who do not respond to GFD by improved mucosa lesions. Serum antibodies have poor sensitivity after staying on GFD longer than 1 year or even more. The RCD is defined just clinically: either as a recurrence of CD symptoms after a former period of response to GFD, or some kind of duodenal deterioration despite of the strict GFD in cases which had been verified clinically and confirmed either serologically or by previous biopsies. Some of latter patients with more severe (Marsh type 3) but GFD non-responding histological lesions may develop complications such as ulcerative jejuno-ileitis or enteropathy type I - associated T-cell lymphoma (EATL). The lymphocytes of the intestinal infiltrate when gaining an aberrant phenotype and genotype undergo clonal expansion then developing EATL. They might represent a gradual stepwise transformation starting from increased accumulation of IEL, probably developing the refractory celiac disease and subsequent lymphoma in situ. These transformational stages of the progressing celiac disease show increasing risk of type 1 EATL development, which decreases the survival of such patients [44]. In EATL patients as result of deterioration of the intestinal mucosa may or may not show ulcerations [45].

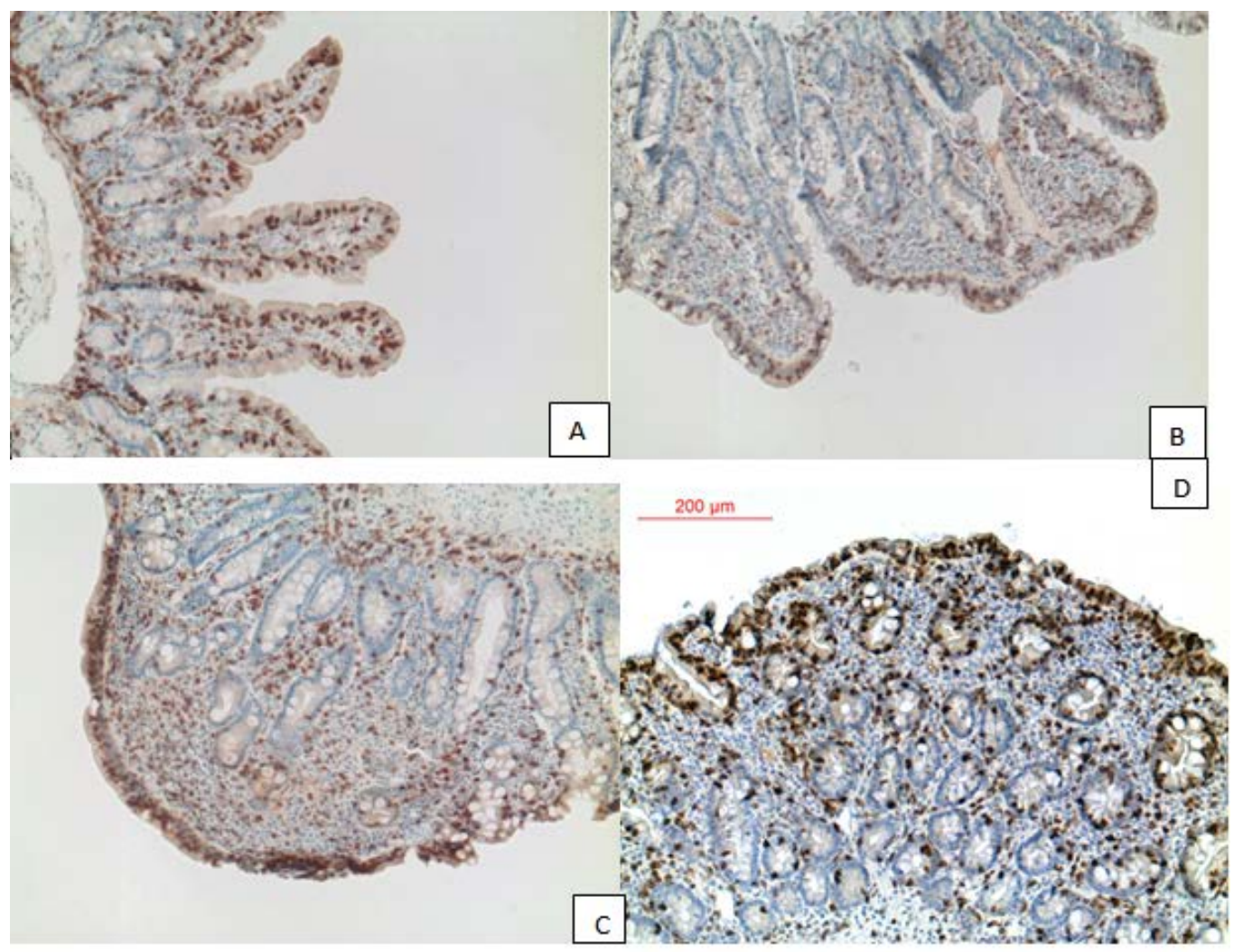

Figure 4. Various type CD lesions in duodenal biopsy by as seen by CD3 lymphocyte staining: the early infiltrative lesion (A) compared with the classical lesion (B, partial atrophy) as well as with progressed lesions (C and D) showing subtotal atrophy

Figure 4A (above in the left): infiltrative lesion of duodenal mucosa shows normal villi, but abundant IEL (Marsh type 1, stage 1, grade A). Figure 4B (above in the right) shows classical lesion with subtotal atrophy of villi, reduced size of enterocytes, abundant IEL and hyperplastic crypts (Marsh 3b, stage IIIB, grade B1). Figure 4C and 4D show progressed lesions (Marsh type 3C, stage IIIC, grade B2) with subtotal atrophy of villi, which are lined by cuboidal (not differentiated) epithelium cells; in addition hypertrophic crypts, abundant IEL as well as abundant lymphocyte infiltration in the lamina propria can be seen.

It should noticed that biopsy sampling in the bulb and/or distal duodenum alone would yield sufficient histological results, i.e. may neither confirm nor exclude the diagnosis of CD [46], especially not in the absence of positive serologic results (see below). The histological lesions in CD may be patchy rather than diffuse and/or they may be confined to the bulb. Data, although scanty, suggests that pathologic lesions involve only $30-50 \%$ of the entire small bowel mucosa [47]. Interestingly enough, in a small proportion of cases the ileum biopsy may display more severe lesions than the duodenal sites. A mild IEL infiltration accompanied with eosinophilic leukocytes can be seen in the colon mucosa as well. Current guidelines recommend obtaining multiple biopsies from the bulb as well as distal duodenum when evaluating for CD. Adherence to these recommendations among gastroenterologists treating adults is low, and unfortunately, there are no overall accepted recommendations at all available for pediatric gastroenterologists [48].

\section{Pathogenesis of Celiac Disease}

As already mentioned, CD is an autoimmune disorder occurring in genetically susceptible individuals, who reveal certain human leukocyte antigen (HLA) class II haplotypes, when expressing either the DQ2 [DQA*0501DQB*0201] or the DQ8 [DQA*0301-DQB1*0302] regions. The HLA II molecules function as co-receptors of antigen presenting cells (APC) involved in the processing of exogenous antigens. The APCs are dendritic cells, macrophages and/or other phagocytes engulfing foreign protein antigens. These are first cleaved and then their 
immunogenic peptides are presented to antigen recognizing receptors of reactive $\mathrm{T}$ cells, such as the $\mathrm{CD}^{\text {plus }} / \mathrm{CD} 4^{\text {plus }}$ helper T-lymphocytes [49]. Structural polymorphisms of major histocompatibility complex subloci identify the codon switches within the second exon that control the third hyper variable region in the outer domain of HLA II molecule. The shape of different grooves formed by the subunits of HLA II molecule subtypes, confers a kind of affinity for capturing a certain antigenic peptide. When presented at the APC surface, this mechanism may explain the restricted genetic susceptibility for the development of CD, associated with a pathologic immune response to gluten and related prolamins [50]. Several prolamins (of wheat, rye, and barley) contain recurring tetrapeptide motif sequences that are predicted to have a beta-reverse-turn secondary structure, appearing active at least by in vitro assays [47]. The immune-mediated responses in jejunal tissue at gluten sensitivity arise in the lamina propria, in association with macrophages and the in abundance activated $\mathrm{CD}^{\text {plus }} / \mathrm{CD}^{\text {plus }}$ T-lymphocytes (helper T-cells). Many other inflammatory consequences flow from these interactions, involving activation of mast cells, eosinophil and neutrophil granulocytes, induction of cytokines (such as IL-15) and other products of inflammation, along with increased hyper permeability of the microvasculature and up regulation of leukocyte adhesion molecules. The result is a doubling of the volume of lamina propria connective tissue accompanied with a less or more severe flattened villi lined by low differentiated enterocytes indicating local inflammation and proliferation [30,47,51]. The gliadin peptide (a cleavage product of gluten), in addition evokes the dose-responsive infiltration of the surface enterocyte layer with $\mathrm{CD}^{+} / \mathrm{CD}^{+}$T-lymphocytes (forming the IEL described above). The $\mathrm{T}$ cell receptors (TCR) of the IEL cells consist of gamma-delta subunits, i.e. of different protein chains. The $\gamma \delta \mathrm{TCR} \mathrm{CD}^{+} / \mathrm{CD}^{+} \mathrm{T}$ lymphocytes then function as local intraepithelial cytotoxic T cells. Unlike to $\alpha \beta \mathrm{CD}^{+}{ }^{+}$T-cells, the $\gamma \delta \mathrm{CD} 3^{+}$ $\mathrm{T}$-cells had not undergone antigen selection rendering them tolerant to the self (own body) antigens.

In ingested food, the gluten molecule (which precipitates the pathological immune response) is cleaved by luminal and/or brush-border enzymes of enterocytes into amino acids and $\alpha$-gliadin peptides that are resistant to further degradation. It has been hypothesized that the increased intestinal permeability (as manifested by above mentioned decrease in expression of junction proteins) is an early but crucial event supporting the transport of $\alpha$ gliadin through the epithelial barrier by a not well defined paracellular mechanism and/or by apical-to-basal transcytosis [52]. After crossing the epithelial cell barrier and entering lamina propria, the $\alpha$-gliadin peptides are cross-linked, and their charged glutamic acid residues are deamidated by tissue transglutaminase 2 (tTGase 2), to produce deamidated glutamine peptides (DGP). The DGP molecules are bound with high affinity either to DQ2 or to DQ8 HLA II receptor molecules expressed on the surface of APCs. In such way, when inducing the $\mathrm{CD}^{\text {plus }} / \mathrm{CD} 4^{\text {plus }}$ T-cell-specific responses, their help provided to B cells elicits the gluten specific antibody response (this antibody is not an autoantibody). Gliadin is also thought to stimulate the innate immune system among intestinal epithelial cells directly or through the up regulation of IL-
15. The IL-15 cytokine has been recognized to upregulate the MIC-A, a stress molecule on enterocytes and the NKG2D receptor of NK (natural killer) cells, promoting an initial enterocyte damage. IL-15, in turn, activates altered signaling through NK/G2D and other CD94/NKG2 receptors, and on the CD45 (transmembrane tyrosine kinase) molecules of IELs, whose cognate ligands on intestinal epithelial cells are also upregulated by IL-15 and IFN- $\gamma$. Taken together, the complex mechanism of CD lesions is mediated: 1. By the innate immunity provided through NK cells and 2. By IELs, both of which are involved in early as well as in late phases of CD pathogenesis, 3. By the role of cytokines such as IL-15 and IFN $\gamma$, thought to underlay the increased release of tissue TGase 2 that leads to deamidation of gluten peptides, and 4. By the sequence of, and/or for the relationship between the helper $\mathrm{CD}^{+} \mathrm{T}$ cell responses and intestinal B cells, stimulating local IgA production in the patients who develop CD. The inflammatory cytokines, the apoptotic proteins (granzyme $\mathrm{B}$ and perforin), and activated cytotoxic proteins (metallo-proteinases) may also be responsible for the early damage to intestinal tissue as seen in biopsy specimens coming from CD patients [20]. Furthermore, autoantibodies are formed against the own tissue enzymes such as tTGase 2 (expressed in increased amounts) along with the anti-DGP autoantibodies.

\section{Celiac Disease versus Inflammatory Bowel Disease: Serological Markers and Differential Diagnostic}

AS already mentioned, the diagnostic signs of CD (which complement duodenal biopsy) are the presence of critical HLA-DQ2 and/or HLA-DQ8 haplotypes in susceptible patients and their still healthy relatives, the diverse but occasionally typical clinical manifestations (summarized in Table 1) and the production of special autoantibodies and anti-gliadin antibodies (summarized in Table 6). Out of the latter, the traditional anti-endomysium antibodies (AEmA) can be detected by indirect fluorescent antibody (IFA) test [53]. Sections from intestinal mucosa show positive AEmA staining in their lamina propria, while the fine reticular (honey comb-like) fluorescence within the subepithelial connective tissue of villi indicates the reaction of the antireticulin antibody (ARA). The detection of ARA, as described by Calvani et al. [54], even though useful in basic screening, is much less specific than that of AEmA. Nevertheless, the presence of both, AEmA and ARA together, predicts the diagnosis of CD with a high probability [55,56]. When using the endomysium/gliadin diagnostic mosaic kit (Euroimmun) consisting of sections of primate liver, rat oesophagus and/or small intestine along with the gliadin coated microdots (taking advantage of a pure and specific gliadin antigen), the parallel detection of antibodies to gliadin along with AEmA and ARA is of great diagnostic value [57]. Later on, the AEmA has turned out to react with the tTGase 2 antigen being overexpressed in lamina propria along with DGP produced from the digested gluten at same site. The physiological activity of tTGase 2 as well as its amount expressed in the gastric and/or intestinal 
mucosa are enhanced in CD patients, since the production of this enzyme becomes activated in order to cleave the gluten in the ingested food into gliadin. Both autoantibodies are typical for CD and, if present together, they are considered for CD specific. Therefore, it is recommended to confirm the results of positive AEmA as found by IFA screening, by the detection of antibodies to tTGase 2 and to DGP by appropriate ELISA tests [58,59]. It is up most useful to determine the tTGase 2 antibody reactivity also in the IgA immunoglobulin class. Most recently, microdot slides and/or the ELISA microplates are available coated with a highly specific gliadin peptide, consisting of two but three times repeated gliadin-specific epitopes (GAF-3x). In either modification, the anti-gliadin antibody (AGA) test shows high specificity and significance. Nevertheless, the widely accepted serological tests available for CD still call for standardization, in order to compare the results from different laboratories [60].
According to novel recommendations, if the IgA antitTGase 2 antibody level shows a value greater than the 10fold cut-off, such result can be regarded for quite satisfactory for decision making without an additional need of duodenal biopsy [61]. However, this notion was seriously challenged by the findings of Makovický et al. [25], who documented that certain pediatric patients may be seronegative while the disease is already active, so that the incidence of $\mathrm{CD}$ in the pediatric population is higher than expected from serological results. This is an important finding, which demonstrates the lack of a strict association between autoantibodies and lesions. It justifies the use of biopsies for conformation diagnosis in any case when negative serology does not correlate with clinical symptoms. Therefore, some diagnostic algorhitms, based on comparing the clinical, endoscopic and serological context, should be reconsidered (see legend to Figure 5).

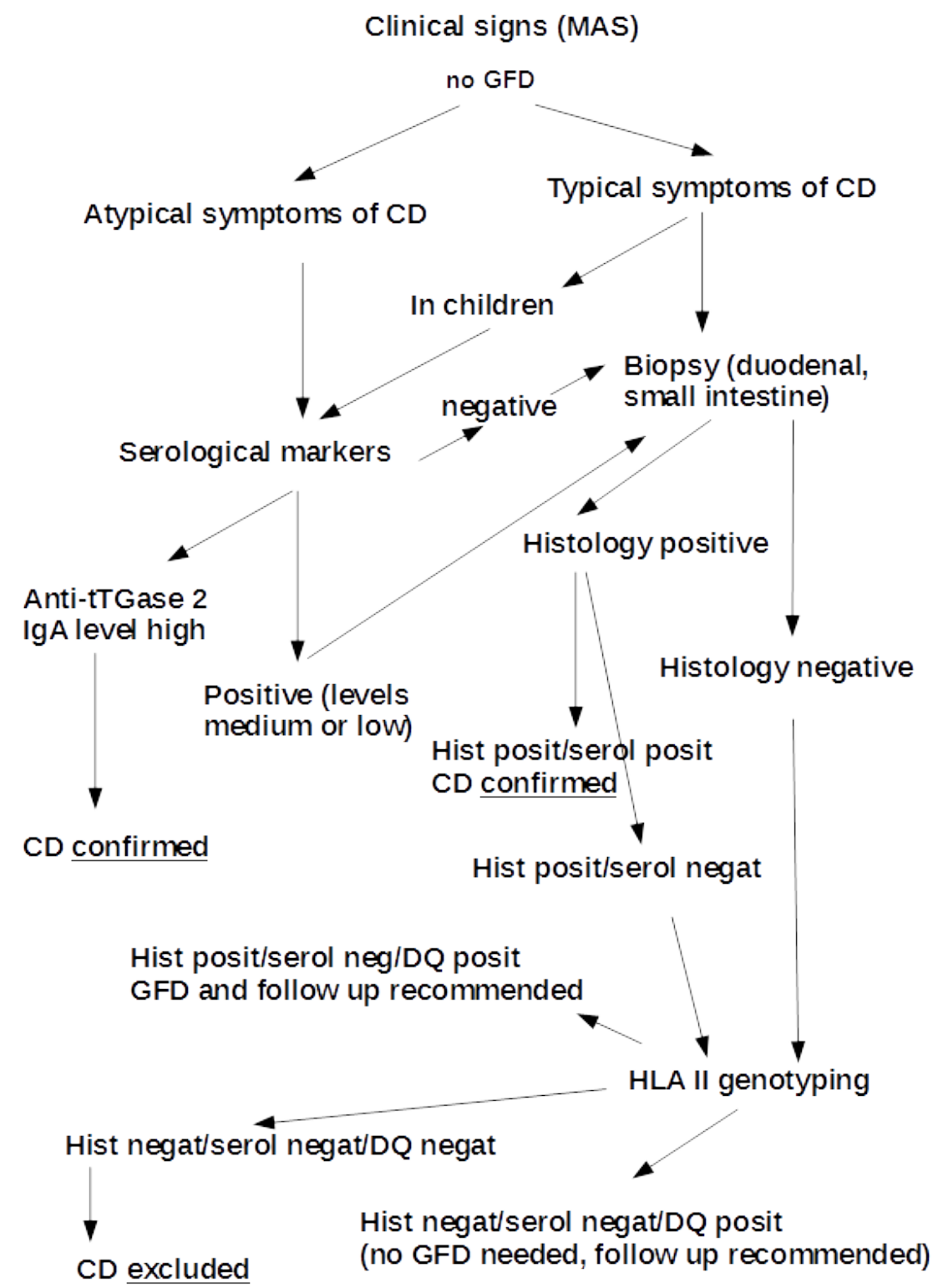

Figure 5. The presented diagnostic algorhitm takes into account that extremely high anti-tTGase 2 IgA levels (reaching tenfold of the borderline value defined by Vermeersch et al. [61]) may confirm the diagnosis of CD without biopsy. In the case of medium and/or lower anti-tTGase 2 levels, duodenal biopsy should be taken to confirm the results of serology. The serology is a prior (first) choice in children and in adults, whose clinical symptoms are neither typical nor relevant. Even if the serological markers cannot be regarded in CD diagnostic for absolutely superseding, their advantage is in simplicity, high specificity and in noninvasive way of sampling. In cases showing typical symptoms, vice versa, the serology is at second line of choice, especially important for confirming the diagnosis in cases of uncertain biopsy results. Finally, for the therapeutic strategy when serology is positive, but histology negative, an assessment of inherited risk by HLA II DQ genotyping seems inevitable. 
Table 5. Statistical analysis of the serology versus biopsy in both possible orders ${ }^{1}$

\begin{tabular}{|c|c|c|c|c|c|c|}
\hline Diagnosis & $\begin{array}{l}\text { No of samples } \\
\text { submitted }\end{array}$ & $\begin{array}{l}\text { Total tested } \\
\text { by IFA * }\end{array}$ & $\begin{array}{l}\text { Total tested by IFA* as } \\
\text { well as by AGA** }\end{array}$ & $\begin{array}{l}\text { AGA positive } \\
\text { out of tested }\end{array}$ & $\begin{array}{l}\text { Confirmed by } \\
\text { biopsy }\end{array}$ & $\begin{array}{l}\text { Proportion } \\
\text { of BP/SP }\end{array}$ \\
\hline \multicolumn{7}{|c|}{ Serology performed first } \\
\hline $\mathrm{CD}$ & 1054 & 1054 & $975(92.5 \%)$ & $59(6.1 \%)$ & $29(3 \%)$ & $49.1 \%$ \\
\hline MAS*** & 482 & 482 & $415(86.1 \%)^{3}$ & $21(5.0 \%)$ & $21(5.1 \%)^{3}$ & $100 \%$ \\
\hline Total & 1536 & 1536 & $1390(90.1 \%)$ & $80(5.8 \%)$ & $50(3.5 \%)$ & $62.5 \%$ \\
\hline \multicolumn{7}{|c|}{ Biopsy performed first } \\
\hline & $\begin{array}{l}\text { Number of patients } \\
\text { examined by biopsy }\end{array}$ & $\begin{array}{l}\text { Histology } \\
\text { positive }^{4}\end{array}$ & $\begin{array}{l}\text { Histology Marsh } \\
\text { type 3, specificity high }\end{array}$ & $\begin{array}{l}\text { Histology Marsh } \\
\text { type } 1 \text {, specificity low }\end{array}$ & $\begin{array}{l}\text { Histology } \\
\text { negative }\end{array}$ & $\begin{array}{l}\text { Samples/ } \\
\text { patient }\end{array}$ \\
\hline $\mathrm{CD}$ & 345 & $153(44.3 \%)$ & $70(20.2 \%)$ & $83(24 \%)^{5}$ & $140(43.2 \%)$ & $4.3 \_+1.9 * * * *$ \\
\hline MAS*** & & & $52(15 \%)^{5,6}$ & & & \\
\hline
\end{tabular}

*indirect immunofluorescence assay (AEmA and ARA); notice: in 79 CD and/or in 67 MAS patients, respectively, the CD markers were tested along with ANA or ANCA; of these, no sample was positive for AEmA and/or ARA.

$* *$ anti-gliadin antibody as detected by microdot test

***nutrient absorption disorders which were either non-gliadin related allergic reactions [145], TM (2 cases) or others classified as unknown [335] in origin. The AGA positive rates in these individual groups were 5/135 (3.7 \%) for the former and 16/335 (4.7\%) for the latter, respectively.

$* * * *$ arithmetic mean and its standard deviations

${ }^{1}$ Serology was done first and later on confirmed by biopsy (upper part); lower part shows the results, when biopsy was done first. Note: selected patients

(showing suspicious or non-specific lesions) were recommended for serological marker testing.

${ }^{2} \mathrm{BP}$ (biopsy positive)/SP (serology positive)

${ }^{3}$ this group also includes the 6 AGA negative but biopsy positive cases $(1.5 \%)$

${ }^{4}$ all the Marsh types together

${ }^{5}$ serology recommended by the pathologist

${ }^{6}$ declared as non-CD (other type of allergy or duodenitis), villous atrophy missing, occasionally Helicobacter pylori present. Recommended for serology to exclude the diagnosis of CD.

The clinicians, on one hand, take an advantage of serological marker testing due to their simplicity and lower costs. According to our general experience, the IFA test combined with microdot and immunoblot assays can be regarded for representative and may be preferentially used by the pathologist [62]. For this reason, were perform the AEmA, ARA and AGA testing together, i.e. in the same serum sample using the endomysium/gliadin diagnostic mosaic kit. It comes from our statistics that during the last 3 years (from 2012 to 2014) out of 975 serum samples examined by AGA, the diagnosis of CD was positive in $6.1 \%$. This frequency is in compliance with the positive ratios observed at our Diagnostic center by other autoantibody screening tests. Alternatively, however, from the 415 serum samples submitted from the patients under the diagnosis of MAS, nearly the same proportion (5\%) was AGA positive (Table 5). Taken together, the serological screening for $\mathrm{CD}$ in suspicious patients revealing atypical or unclear clinical signs, revealed an average positive rate of $5.8 \%$, represented by 80 AGA positive patients. From these, over the half has been checked by duodenal biopsy in order to confirm the diagnosis. In those cases, when biopsy was performed at first choice, clear-cut and progressed CD lesions were seen in $20.2 \%$ cases confirming the clinical diagnosis without the need of any serology. Additional $24 \%$ of duodenal biopsies showed mild lesions, which could not been always regarded for $\mathrm{CD}$-specific. In these, but also in MAS patients showing no relevant CD lesions, serological tests were recommended by the pathologist in order to clarify the diagnosis. Thus, in above mentioned cases serology is needed either to confirm or exclude the diagnosis of CD. Serology namiesto it is further useful for repeated follow up of suspicious cases with negative histology, especially when the patients express the high risk DQ2 [DQA*0501-DQB*0201] or DQ8 [DQA*0301DQB1*0302] HLA II regions (Figure 5).

Table 6. Serological markers in CD and inflammatory bowel disease

\begin{tabular}{|c|c|c|c|c|c|}
\hline Clinical entity & Autoantibody & Antigen & IFA & IB & ELISA \\
\hline Celiac disease (CD) & $\begin{array}{l}\text { AEmA, ARA } \\
\text { AGA } \\
\text { anti-DGP }\end{array}$ & $\begin{array}{l}\text { tTGase }^{1} \\
\text { gliadin, }(\alpha) \text {-gliadin peptide } \\
\text { deamidated }(\alpha) \text {-gliadin peptide }\end{array}$ & $\begin{array}{l}\text { Liver/oesophagus/intestine } \\
\text { sections } \\
\text { Microdots coated by the GAF- } \\
\text { 3X nonapeptide }{ }^{2}\end{array}$ & Not available & $\begin{array}{l}\text { Anti-tTG (IgA, IgG) } \\
\text { Anti-TGase } 2 \\
\\
\text { GAF-3X (IgA, IgG) } \\
\text { Anti-DGP }\end{array}$ \\
\hline Ulcerative colitis & $\begin{array}{l}\text { pANCA* } \\
\text { GAB }^{3}\end{array}$ & $\begin{array}{l}\text { lactoferrin (DNA bound), } \\
\text { histone H1 }\end{array}$ & $\begin{array}{l}\text { Granulocytes (smear ethanol } \\
\text { fixed) } \\
\text { Adenocarcinoma line HT29- } \\
\text { 18N2 }\end{array}$ & \begin{tabular}{|l|} 
MPO/PR3 \\
strip* \\
Not available
\end{tabular} & MPO ELISA \\
\hline Crohn's disease & $\begin{array}{l}\mathrm{PAB}^{4} \\
\mathrm{ASCA}^{5}\end{array}$ & $\begin{array}{l}\text { CUZD1/rPAg1 (zymogen granule } \\
\text { membrane protein) } \\
\text { GP2/rPAg2 (acinus cell proteoglycan) } \\
\text { GPI }^{6} \\
\text { Bacterial glycans } \\
\text { Pseudomonas fluorescence antigens }\end{array}$ & $\begin{array}{l}\text { HEK296-CUZD1 transfected } \\
\text { cells } \\
\text { HEK293-GP2 transfected cells }\end{array}$ & Not available & $\begin{array}{l}\text { ALCA }^{7}, \\
\text { ACCA }^{8}, \\
\text { AMCA }^{9}, \\
\text { anti-L }^{12}, \\
\text { anti-C }{ }^{13} \\
{ }^{10} \text { anti-ompC, } \\
{ }^{11} \text { anti-I2 }\end{array}$ \\
\hline
\end{tabular}

${ }^{1}$ tissue transglutaminase; ${ }^{2}$ nonapeptide, a 3 times repeated oligopeptide construct (gliadin specific) ${ }^{3}$ goblet cell antibody ${ }^{4}$ (exocrine) pancreas acinus antibody ${ }^{5}$ anti- Saccharomyces cerevisae antibody ${ }^{6}$ Glycosyl-phosphatidyl-inosine; ${ }^{7}$ anti-laminaribinoside carbohydrate antibody; ${ }^{8}$ anti-chitobioside carbohydrate antibody; ${ }^{9}$ anti-mannobioside carbohydrate antibody; ${ }^{10}$ outer membrane porin C, ${ }^{11}$ Pseudomonas fluorescens protein I2 ${ }^{12}$ laminin ${ }^{13}$ chitin. *perinuclear anti-neutrophil cytoplasmic antibodies (reacts with the myeloperoxidase antigen, MPO, seen mainly in perinuclear localization); cANCA (cytoplasmic ANCA) reacts with proteinase 3 (PR3) antigen located throughout the cytoplasm. The rare xANCA reacts with other enzymes such as cathepsin $\mathrm{G}$ and/or elastase mainly associated with lysosomes.

In contrast to $\mathrm{CD}$, the intestinal bowel disease (IBD) is a designation for two practically different clinical entities,

namely ulcerative colitis (UC) and Crohn's disease. While the former is characterized by inflammatory lesions 
located at the surface mucosa of large intestine (especially in colon sigmoides and upper rectum areas), in Crohn's disease slowly developing deep transmural granulomatous inflammation involves mainly the terminal ileum. In UC the intestinal mucosa goblet cell antibody (GAB) predominates along with the ANCA-like antibodies, which react with the $\mathrm{H} 1$ histone and the mycobacterial histone 1 homologue called Hup B. In general, UC is characterized by the presence of blood granulocyte reactive antibodies (pANCA and xANCA), which are relatively frequent. Namely, pANCA occurs with the probability ranging from 75 to $100 \%$, while xANCA appears by the probability of $50 \%$, while the frequency of cANCA is rare, just at about $10 \%$ [63]. In contrast, in the pANCA antibody appears rarely in Crohn's disease (less than $20 \%$ probability), but more frequently, by at least $40 \%$ of patients, autoantibodies to exocrine pancreas (acinus cells) can be found (Table 6, see legend for explaining the details).

A presumed etiological mechanism of IBD is the dysregulated immunopathologic response to certain antigens of the own bacterial flora [64]. Namely, in Crohn's disease heterologous antibodies have been found reacting with epitopes of Bacteroides caccae (Ton-B linked outer membrane protein) and Pseudomonas fluorescens associated bacterial protein I-2. More recently, the chance of correct IFA diagnostic in Crohn's disease has been improved by introducing the so called CIBD mosaic (Euroimmun), in which the pancreas sections used to detect the pancreas antibodies (PAB), were replaced with recombinant pancreas acinus cell antigens (rPAB/Ag1 and/or rPAB/Ag2). Namely, the mosaic contains two transfected cell lines: HEK-293-CUZD1 expressing the zona pellucida (CUB) domain protein (CUZD1) corresponding to the exocrine acinus zymogen granule membrane protein and the transfected HEK293GP2 cell line expressing the pancreas glycoprotein GP2 [65]. Furthermore, the CIBD mosaic in question contains the human adenocarcinoma cell line HT29-18N2 producing a goblet cell-like antigen in vitro, which is identical with that present in primate intestinal goblet cell sections as confirmed with a series of various lectins [66]. Summing up, in UC pANCA and GAB predominate, while in Crohn's disease the PAB prevails along with heterologous antibodies to the yeast (Saccharomyces cerevisae) surface antigen (ASCA), which occurs with a frequency of about $90 \%$. The detection of ASCA by IFA is quite reliable, while additional heterologous antibodies reacting with several bacterial glycans (ALCA, ACCA, AMCA, anti-L anti-C) and/or above mentioned Pseudomonas fluorescence antigens can be identified by ELISA. Nevertheless, the latter antibodies are not quite specific for Crohn's disease, so that in the absence of ASCA their significance seems questionable [67].

\section{Disorders Closely Related to CD and Their Diagnostic}

Strong associations between $\mathrm{CD}$ and various autoimmune diseases, including autoimmune thyroid disease, type 1 diabetes mellitus, primary biliary cirrhosis, inflammatory bowel diseases and autoimmune adrenal insufficiency, have been demonstrated. It is believed that $2-5 \%$ of patients with autoimmune thyroid disorders have celiac disease, due to common genetic characteristics $[68,69]$. Hyperplasia of crypts, as mentioned in Table 3 and Table 4, occurs in several other MAS related conditions such as TM; relatively rarely it can be found in diabetes and in dermatitis herpetiformis (DH). The $\mathrm{DH}$ is a chronic blistering skin lesion, which is neither related to nor caused by herpes virus: the name just means that its appearance looks similar to herpes. When first described by L. A. Duhring in 1884, it was characterized as a skin disease of unknown etiology. The connection with celiac disease was recognized in 1967, but confirmed just recently by the presence of CD-related serologic markers [70] along with the association to HLA-DQ2 haplotype and gluten sensitivity [71,72]. Despite of the belief that $\mathrm{DH}$ is a quite specific manifestation of $\mathrm{CD}$, the exact causal mechanism of skin lesion formation is still obscure. The skin affected by $\mathrm{DH}$ presents edema of epidermis, infiltration by neutrophil granulocytes and IgA deposits. The latter have an increased prevalence in the dermis, namely its closest areas to the epidermis. The direct IFA staining (anti-HuIgA/FITC) of uninvolved skin shows IgA deposits in dermal papillae and patchy granular IgA accumulation along the epidermal basement membrane. The biopsy of jejunal mucosa shows a lower degree of partial villous atrophy, and in addition, many hyperplastic crypts. In contrast, hypoplasia of crypts can be seen in severe cases of TM, in some cases of progressed (late) stage $\mathrm{CD}$ at the and in cases which are unresponsive to GFD (compare the upper paragraph). In adults with steatorrhea, deposition of collagen in the lamina propria is not an unfrequent change seen in duodenal biopsy samples obtained by the end-stage of CD.

In allergic enteropathy which develops in response to allergens (antigens) other than gluten, the mucosal connective tissue is infiltrated by eosinophilic granulocytes, but neither villous atrophy, nor altered crypts and/or no increased IEL can be seen. In progressive lymphoid hyperplasia, the jejunal mucosa reveals large secondary follicles, while the germinal centers regularly present in ileum mucosa become overshadowed by the massive and diffuse lymphocyte infiltration. Hypogammaglobulinemia is a form of primary immunodeficiency, as an uncommon condition in which gastrointestinal symptoms may be the only presentation [73]. In duodenal mucosa biopsies of such patients, the morphologic picture of massive infiltration in lamina propria by plasma cells, occasional villous atrophy and nodular lymphoid hyperplasia can be found. Serum globulins are low in all the patients. As result of severe immunodeficiency, the concomitant opportunistic infections may include intestinal parasites (giardia, lamblia, Cryptosporidium parvum, Isospora belli) and/or cytomegalovirus. If hypogammaglobulinemia accompanies IBS (may result into MAS), it may be combined with recurrent upper and lower respiratory tract infections, defective antibody responses, a granulomatous disease mimicking sarcoidosis and/or lymphoma (usually of B-cell origin). This rare disorder also called common variable immunodeficiency (CVIS) is difficult to manage [74]. The so called Waldenström macroglobulinemia (WM) has been initially thought to be associated with a variety of lymphoid neoplasms that can secondarily cause hyperviscosity syndrome. Subsequently, the WM combined with lymphoplasmacytic lymphoma (LPL) and had been designated lymphoplasmacytic lymphoma/Waldenström 
macroglobulinemia [75]. In the latter disease, jejunal mucosa shows extracellular deposits of PAS positive material in the connective tissue of lamina propria, which surrounds the lymphatic vessels and/or distends their internal lumen. The results of flow cytometry show that the immunophenotype of LPL/WM is variable, but overlaps mainly with that of other B-cell lymphoproliferative disorders [76]. In contrast, in Whipple disease the connective tissue of villi is infiltrated with large mononuclear phagocyes, which cytoplasm is filled in with PAS positive material showing rod shaped or granular appearance. Jejunal biopsy plays important role in the detection of lymphangiectasaia which is associated with severe protein loss and closely related to CD, to TM, to giardiases but occasionally also to Crohn's disease. The mucosal lymphatics within the tips of villi are extremely widened in the absence of any villous atrophy. The lamina propria may contain scattered macrophages filled with PAS positive granules and/or fat droplets. Waldman et al. [77] reported the first cases of such intestinal lymphangiectasia, associated with edema and hypoproteinemia (along with hypoalbuminemia and hypogammaglobulinemia). Biopsies of the small bowel [78] showed prominent dilated lymphatics in the lamina propria region, often with extension into submucosa, but this lesions may be quite focal. A rare association of the intestinal lymphangiectasia with CD has been noted [79]; however, in most with primary intestinal lymphangiectasia, the intestinal villi appear to be otherwise normal on routine microscopic evaluation apart from the dilated lacteals. In addition, iron deficiency may develop [80] but it is not clear if there is any impairment of iron absorption in primary intestinal localized in the duodenum. The disease, as a rule, occurs in small children, often in neonates, but is rare in adults. A critical diagnostic element in adults with lymphangiectasia is the exclusion of malignancies including lymphoma, Whipple's disease or chronic inflammatory disorders such as Crohn's disease, all of which may cause MAS or at least profound changes in intestinal permeability and/or protein-losing enteropathy [81]. Whipple disease is a rare, multi-organ disease with prominent intestinal manifestations. Clinical signs preceding the diagnosis are articular, digestive (MAS) and/or neurologic. At progressed stage of the disease, patients present diarrhea, weight loss and some other symptoms of MAS, though a minority does not show any gastrointestinal symptomatology. In Whipple disease, histopathology is the key for differential diagnosis, but may this may require multiple and occasionally even repeated sampling. AS a rule, the villous pattern looks distorted by conspicuous infiltrate consisting of large mononuclear cells PAS positive material. The macrophages are located in loose connective tissue of widened villi containing neutral fat. The central role of PCR has been confirmed for the detection of the associated Gram-positive bacillus named Tropheryma whippelii, which otherwise is very difficult to culture [82].

\section{Conclusions}

The main structural features of CD, as seen in duodenal biopsy, include villous atrophy at the small intestine mucosa along with crypt hyperplasia and of $\mathrm{CD}^{\text {plus }} \mathrm{T}$ lymphocyte infiltration of the intraepithelial compartments
(IEL). Later on, the inflammatory T-lymphocyte accumulation in the lamina propria becomes abundant. In the past, duodenal biopsy was regarded for the golden diagnostic standard which should be always performed in order to confirm the diagnosis of CD. However, in patients who show atypical and/or incomplete clinical symptoms, the reasonable strategy is to examine the welldefined and highly significant serological markers first. Serological tests include screening of AEmA by IFA, detection of tTGase 2 antibodies (especially in the IgA class) by ELISA and/or detection AGA using the so called microdots as antigen. The serologic markers are of great importance; when positive, they are indicative for the running $\mathrm{CD}$. Thus, relatively simple and non-invasive serological tests can ensure that either asymptomatic individuals or those with mild (atypical) clinical forms are identified. Patients who are serologically positive for CD, but still show normal histology, represent its latent form. In these, duodenal biopsy may be performed to distinguish between the silent and/or latent cases. Another recently introduced test for solving the latter situation is HLA II genotyping. Those individuals who reveal classical CD symptoms as well as positive serology (at least two or all three markers positive by two different tests) and, in addition, show the high risk HLA II haplotypes (HLADQ2 and/or HLA-DQ8) can be regarded for CD positive even in the absence of convincing duodenal biopsy lesions (Figure 5 shows the alternative diagnostic algorithms). In all cases mentioned above, starting GFD is justified. Repeated duodenal biopsy can be performed in order to follow the patient's response to GFD and to other therapeutic measures previously positive cases, but mainly in adults. On other hand, at repeated testing, the noninvasive serologic follow up is highly recommended especially for children in whom obtaining the biopsy samples might be difficult and/or in those adults who have shown negative or not convincing biopsy.

\section{Abbreviations}

CD - celiac disease (patient disorder), MAS malabsorption syndrome, IBS -irritable bowel disease, TM - tropical malabsorption, SIBO- small intestine bacterial overgrowth, GFD - gluten free diet, IEL intraepithelial lymphocyte, AEmA - anti-endomysium antibody, anti-tTGase 2 - tissue transglutaminase 2 antibody, anti-DGP - deamidated gliadin peptide antibody, AGA - anti-gliadin antibody, SNCD - seronegative celiac disease, TCR - T cell receptor, HLA - human leukocyte antigen, CD - cluster of differentiation (immunocyte marker), APC - antigen presenting cell, PAB - pancreas antibody, UC - ulcerative colitis, ANCA - anti-netrophil cytoplasmic antibody, IL - interleukin, IFN - interferon, IFA - indirect fluorescent antibody (assay), ELISA enzyme linked immunosorbent assay.

\section{References}

[1] Mohan H. The Gastrointestinal Tract, In: Textbook of Pathology, 6th Ed., Jaypee Brothers Medical Publishers Ltd, 2010.

[2] Mathan VI, Baker SJ. Epidemic tropical sprue and other epidemics of diarrhea in South Indian villages. Am J clin Nutr 1968; 21: 1077-1087. 
[3] Ranjan P, Ghoshal UC, Aggarwal R, Pandey R, Misra A et al. Etiological spectrum of sporadic malabsorption syndrome in northern Indian adults at a tertiary hospital." Indian J Gastroenterol 2004; 23:94-98.

[4] Lindenbaum J, Alam AK, Kent TH. Subclinical small intestinal disease in East Pakistan. Br Med J 1966; 2:1616-1619.

[5] Wilde H. Tropical sprue in Thailand. J Med Ass Thai 1974; 57:3240.

[6] Kirchgatterer A, Allinger S, Balon R, Tuppy H, Knoflach P. Tropical sprue as the cause of chronic diarrhea after travel in Southern Asia. Zschr Gastroenterol 1998; 36:897-900.

[7] Bayless TM, Wheby MS, Swanson VL. Tropical sprue in Puerto Rico. Am J Clin Nutr 1968; 21:1030-1041.

[8] Montgomery RD, Chesner IM. Postinfective malabsorption in the temperate zone. Trans Soc Trop Med Hyg 1985; 79:322-327.

[9] Thabane M, Marshall JK. Post-infectious irritable bowel syndrome. World J Gastroenterol. 2009; 15:3591-3596.

[10] Ghoshal UC, Park H, Gwee KA. Bugs and irritable bowel syndrome: the good, the bad and the ugly. J Gastroenterol Hepatol 2010; 25:244-251.

[11] Drasar BS, Shiner M, McLeod GM. Studies on the intestinal flora. I. The bacterial flora of the gastrointestinal tract in healthy and achlorhydric persons. Gastroenterology 1969; 56:71-79.

[12] Gorbach SL. Intestinal microflora. Gastroenterology 1971; 60: 1110-1129.

[13] Vantrappen G, Janssens J, Hellemans J, et al. The interdigestive motor complex of normal subjects and patients with bacterial overgrowth of the small intestine. J Clin Invest 1977; 59: 11581156.

[14] Simon GL, Gorbach SL. Intestinal flora in health and disease. Gastroenterology 1984; 86:174-193.

[15] Husebye E, Skar V, Hoverstad T, et al. Abnormal intestinal motor patterns explain enteric colonization with gram-negative bacilli in late radiation enteropathy. Gastroenterology 1995; 109:1078-1089.

[16] Yakoob J, Abbas Z, Khan R, Hamid S, Awan S, Jafri W. Small intestinal bacterial overgrowth and lactose intolerance contribute to irritable bowel syndrome symptomatology in Pakistan. Saudi J Gastroenterol 2011; 17:371-375.

[17] Posserud I, Stotzer PO, Bjoernsson E-S, Abrahamsson H, Simren M. Small intestinal bacterial overgrowth in patients with irritable bowel syndrome. Gut 2007; 56:802-808.

[18] Ghoshal UC, Ghoshal U, Misra A, Choudhuri G. Partially responsive celiac disease resulting from small intestinal bacterial overgrowth and lactose intolerance. BMC Gastroenterol. 2004; 4: 10.

[19] Ghoshal UC, Ranjan P. Post-infectious irritable bowel syndrome: the past, the present and the future. J Gastroenterol Hepatol. 2011; 26 (Suppl 3):94-101.

[20] Kagnoff MF. Celiac disease: pathogenesis of a model immunogenetic disease. J Clin Investigation 2007, vol. 117 Number 1, http://www.jci.org.

[21] Ghoshal UC, Mehrotra M, Kumar S, Ghoshal U, Krishnani N et al. Spectrum of malabsorption syndrome among adults and factors differentiating celiac disease and tropical malabsorption. Indian J Med Res. 2012; 136:451-459.

[22] Brown IS, Bettington A, Bettington M, Rosty C. Tropical sprue: revisiting an underecognized disease. Am J Surg Pathol. 2014; 38: 666-672.

[23] No authors listed. Revised criteria for diagnosis of celiac disease. Report of working group of European Society of Pediatric Gastroenterology and Nutrition. Arch Dis Child. 1990; 65:909-911.

[24] Brusca I. Overview of biomarkers for diagnosis and monitoring of celiac disease. Adv clin Chem 2015; 68:1-55.

[25] Makovický P, Rimárová K, Boor A, Makovický P, Vodička P et al., Correlation between antibodies and histology in celiac disease: Incidence of celiac disease is higher than expected in the pediatric population. Molec Med Reports 2013; 8: 1079-1083.

[26] Adamkov, M, Boselova, L. Digestive system (alimentary canal), pp.221-250 In: Adamkov M (ed.) Introduction to functional histology, (textbook) P + M Turany 2011, www.p--mtlac.sk.

[27] Rauhavirta T, Lindfors, K, Koskinen O, Laurila K, Kurppa K et al. Impaired epithelial integrity in the duodenal mucosa in early stages of celiac disease. Transl Res 2014; 164: 223-231.

[28] Villanacci V, Ceppa P, Tavani E, Vindigni C, Volta U. Coeliac disease: the histology report. Dig Liver Dis 2011; 43:S385-395.

[29] Marsh, MN, Crowe PT. Morphology of mucosal lesion in gluten sensitivity. Baillier’s Clin Gastenterol 1995; 9: 273-293.
[30] Mino M, Lauwers GY. Role of lymphocyte immunophenotyping in the diagnosis of gluten-sensitive enteropathy with preserved villous architecture. Am J Surg Pathol 2003; 27:1237-1242.

[31] Kakar S, Nehra V, Murray JA, Dayharsh, GA, Burgart LJ. Significance of intraepithelial lymphocytosis in small bowel biopsy samples with normal mucosal architecture. Am J Gastroenterol. 2003; 98: 2027-2033.

[32] Settakorn J, Leong AS. Immunohistologic parameters in minimal morphologic change duodenal biopsies from patients with clinically suspected gluten-sensitive enteropathy. Appl Immunohistochem Mol Morphol 2004; 12:198-204.

[33] Hudacko R, Zhou X-K, Yantiss RK. Immunohistochemical stains for CD3 and CD8 do not improve detection of gluten-sensitive enteropaty in duodenal biopsies. Modern Pathol 2013; 26: 12411245.

[34] Chang F, Mahadeva U, Deere H. Pathological and clinical significance of increased intraepithelial lymphocytes (IELs) in small bowel mucosa. APMIS 2005; 113:385-399.

[35] Salmi TT, Collin P, Reunala T, Mäki M, Kaukinen K. Diagnostic methods beyond conventional histology in coeliac disease diagnosis. Dig Liver Dis 2010; 42: 28-32.

[36] Lindfors K, Koskinen O, Kaukinen K. An update on the diagnostics of celiac disease. Int Rev Immunol 2011; 30:185-196.

[37] Husby S, Koletzko S, Korponay-Szabo’ IR, Mearin ML, Phillips A, et al. European Society for Pediatric Gastroenterology, Hepatology and Nutrition guidelines for the diagnosis of coeliac disease. J Pediatr Gastroenterol Nutr 2012; 54:136-160.

[38] Ludvigsson JF, Bai JC, Biagi F, Card TR, Ciacci C , et al., (24 auhtors of the BSG Coeliac Disease Guidelines Development Group. Diagnosis and management of adult coeliac disease: guidelines from the British Society of Gastroenterology Diagnosis and management of adult coeliac disease: guidelines from the British Society of Gastroenterology. Gut 2014; 63:1210-1228.

[39] Fernandes-Banares, F, CarrascoA, Garcı-Puig R, Rosinach M, Gonzalez C et al. Intestinal Intraepithelial Lymphocyte Cytometric Pattern Is More Accurate than Subepithelial Deposits of AntiTissue Transglutaminase IgA for the Diagnosis of Celiac Disease in Lymphocytic Enteritis. PLOS ONE 2014; 9:e101249.

[40] Lee SK, Lo W, Memeo L, Rotterdam H, Green PH. Duodenal histology in patients with celiac disease after treatment with a gluten-free diet. Gastrointest Endocs 2003; 57:187-191.

[41] Tuire I, Marja-Leena L, Teea S, Katri H, Jukka P et al. Persistent duodenal intraepithelial lymphocytosis despite a long-term strict gluten-free diet in celiac disease. Am J Gastroenterol. 2012; 107:1563-1569.

[42] Ierardi E, Losurdo G, Piscitelli D, Giorgio F, Sorrentino C et al. Seronegative celiac disease: where is the specific setting? Gastroenterology and Hepatology From Bed to Bench. (C)2015 RIGLD, Research Institute for Gastroenterology and Liver Diseases.

[43] Rostom A, Murray JF, Kagnoff MF. American Gastroenterological Association (AGA): Institute Technical Review on the Diagnosis and Management of Celiac Disease. Gastroenterology 2006; 131:1981-2002.

[44] Plank, L. Primary Intestinal Malignant Lymphomas Associated With Celiakia - A Pathologist's Review. International Journal of Celiac Disease 2015;3:59-68.

[45] Müller-Hermelink, H.K., Delabie, J., Ko, Y.H., Jaffe, E.S., Nakamura, S, T-cell lymphoma of the small intestine, IARC, Lyon, 2010, 112-114.

[46] Caruso R, Mafini I, delVecchio Blanco D, Fina D, Paoluzi OA et al. Sampling of proximal and distal biopsies in the diagnosis and monitoring of celiac disease. Dig Liver Dis 2014; 46: 323-329.

[47] Marsh MN. Gluten, major histocompatibility complex, and the small intestine. A molecular and immunobiologic approach to the spectrum of gluten sensitivity ('celiac sprue'). Gastroenterology 1992; 102:330-354.

[48] Ofei S, Boyle B, Ediger T, Hill I. Adherence to Endoscopy Biopsy Guidelines for Celiac Disease: A Pediatric Institutional Analysis. J Pediatr Gastroenterol Nutr. 2015 Apr 24; in press.

[49] Sullivan KE, Magira EE. Immunogenetics, pp.367-386, In: Bellanti JA, Escobar-Gutiérez, A, Tsokos GC (Eds). Immunology (IV): Clinical Applications in Health and Disease. I Care Press, Bethesda, MD, 2012.

[50] Setty M1, Hormaza L, Guandalini S. Celiac disease: risk assessment, diagnosis odstránit' čiarku, and monitoring. Mol Diagn Ther. 2008; 12:289-298. 
[51] Shuppan D, Junker Y, Barisani D. Celiac disease: from pathogenesis to novel therapy. Gastroenterology 2009; 137: 19121933.

[52] Rubio-Tapia, A., and Murray, J. Celiac Disease. Curr Opin Gastroenterol 2010; 26:116-122.

[53] Chorzelski, TP., Sulej, J., Tchorzewska, H., Jablonska, S., Beutner, EH. Kumar V.. IgA class endomysium antibodies in dermatitis herpetiformis and coeliac disease. Ann NY Acad Sci 1983; 420: 325-334.

[54] Calvani, M. Jr, Parisi, G, Miotti, AM, Alessandri, C., Notarnicola, MA. Anti-endomysium antibodies: a new marker for the diagnosis and treatment of celiac disease. Pediatr Med Chir 1992; 14:33-36.

[55] Mascart-Leone F, Lambrechts A. Serology of celiac disease: early diagnosis and therapeutic impact. Acta Gastroenterol Belg 1995; 58:388-396.

[56] Nandiwada, S.L., and Tebo, A.E. Testing for antireticulin antibodies in patients with celiac disease is obsolete: a review of recommendations for serologic screening and the literature. Clin Vaccine Immunol 2013; 20:447-450.

[57] Rujner J, Socha J, Barra E, Gregorek H, Madaliński K et al. Serum and salivary antigliadin antibodies and serum IgA antiendomysium antibodies as a screening test for coeliac disease. Acta Paediatr. 1996; 85:814-817.

[58] Maiuri L, Ciacci C, Ricciardelli I, Vacca L, Raia V et al. Unexpected role of surface transglutaminase type II in celiac disease. Gastroenterology 2005; 129:1400-1413.

[59] Dieterich, W., Ehnis, T., Bauer, M., Donner, P., Volta, U., Riecken, EO. and Schuppan, D. Identification of tissue transglutaminase as the autoantigen of celiac disease. Nat Med 1997; 3:797-801.

[60] Stern $\mathrm{M}$ and Working group on serologic screening for celiac disease. Comparative evaluation of serologic tests for celiac disease. J Pediatr Gastroenterol Nutr 2000; 31:513-519.

[61] Veermersch P, Geboes K, Marien G, Hoffman I, Hiele M, Bossuyt $\mathrm{X}$. Defining thresholds of antibody levels improves diagnosis of celiac disease. Clin Gastroenterol hepatol 2013; 11:398-403.

[62] Rajčáni J, Korinkova, L, Bencat M. Detection of autoantibodies by indirect immunofluorescence and related techniques: the pathologist's view. Medical Research Archives 2015; 4:in press.

[63] Kuna AT. Serological markers of inflammatory bowel disease. Biochemia Medica 2013; 3:23-42.

[64] Nakamura RMI, Matsutani M, Barry M. Advances in clinical laboratory tests for inflammatory bowel disease. Clin Chim Acta 2003; 335:9-20.

[65] Stoecker, W., Teegen, B. Probst C et al. CUZD and GP2 are the exocrine pancreas autoantigens in Crohn's disease, pp.463-473. In: Conrad K et al. (ed.) From pathogenesis to Therapy of Autoimmune Diseases: Autoantigens, Autoantibodies, Auroimmunity. 2009, Pabst Sci Publ.

[66] Stoecker W, Otte M, Ulrich S et al. Antibodies against exocrine pancreas and goblet cells in the diagnostic of Crohn's disease and ulcerative colitis. D. Med. Wschr 1984, 109: 1963-1969 (in German).
[67] Davis MK., Andres JM., Jolley CD, Novak DA, Haafiz AB, González-Peralta RP. Antibodies to Escherichia coli outer membrane porin $\mathrm{C}$ in the absence of anti-Saccharomyces cerevisiae antibodies and anti-neutrophil cytoplasmic antibodies are an unreliable marker of Crohn's disease and ulcerative colitis. J Pediatr Gastroenterol Nutr 2007; 45:409-413.

[68] Ch'ng CL, Jones MK, Kingham JG. Celiac disease and autoimmune thyroid disease. Clin Med Res. 2007; 5:184-192.

[69] Barker JM, Liu E. Celiac disease: pathophysiology, clinical manifestations, and associated autoimmune conditions. Adv Pediatr. 2008; 55:349-365.

[70] Marietta EV, Camilleri MJ, Castro LA, Krause PK, Pittelkow MR, Murray JA. Transglutaminase autoantibodies in dermatitis herpetiformis and coeliac sprue. J. Invest. Dermatol. 128:332-335.

[71] Turchin I, Barankin B (2005). "Dermatitis herpetiformis and gluten-free diet". Dermatology Online Journal 11: 6.

[72] Van L, Browning JC, Krishnan RS, Kenner-Bell BM, Hsu S. Dermatitis herpetiformis: Potential for confusion with linear IgA bullous dermatosis on direct immunofluorescence. Dermatology Online Journal. 2008; 14: 21.

[73] Desai L, Kurien RT, Simon EG, Dutta AK, Joseph AJ, Chowdhury SD. Hypogammaglobulinemia-associated gastrointestinal disease a case series. Indian J Gastroenterol. 2014; 33:560-563.

[74] Ardeniz Ö, Bașoğlu ÖK, Günșar F, Ünsel M, Bayraktaroğlu S et al. Clinical and Immunological Analysis of 23 Adult Patients With Common Variable Immunodeficiency. J Investig Allergol Clin Immunol 2010; 20:222-236.

[75] Owen RG, Treon SP, Al-Katib A, et al. Clinicopathological definition of Waldenström's macroglobulinemia: consensus panel recommendations from the Second International Workshop on Waldenström’s Macroglobulinemia. Semin Oncol. 2003; 2: 110115.

[76] Sergej Konoplev, MD, PhD, L. Jeffrey Medeiros, MD, Carlos E. Bueso-Ramos, MD, PhD, Jeffrey L. Jorgensen, MD, PhD, and Pei Lin, MD. Immunophenotypic Profile of Lymphoplasmacytic Lymphoma/Waldenström Macroglobulinemia. Am J Clin Pathol 2005; $124: 414-420$.

[77] Waldmann TA, Steinfeld JL, Dutcher TF, Davidson JD, Gordon RS Jr. The role of the gastrointestinal system in "idiopathic hypoproteinemia". Gastroenterology 1961; 41: 197-207.

[78] Freeman HJ. Small intestinal mucosal biopsy for investigation of diarrhea and malabsorption in adults. Gastrointest Endosc Clin N Am 2000; 10: 739-775.

[79] Freeman HJ, Nimmo M Intestinal lymphangiectasia in adults. World J Gastrointest Oncol 2011 15; 3:19-23.

[80] Perisic VN, Kokai G. Coeliac disease and lymphangiectasia. Arch Dis Child 1992; 67: 134-136.

[81] Iida F, Wada R, Sato A, Yamada T. Clinicopathologic consideration of protein-losing enteropathy due to lymphangiectasia of the intestine. Surg Gynecol Obstet 1980, 151: 391-395.

[82] Durand DV1, Lecomte C, Cathébras P, Rousset H, Godeau P Whipple disease. Clinical review of 52 cases. The SNFMI Research Group on Whipple Disease. Société Nationale Française de Médecine Interne. Medicine (Baltimore). 1997; 76:170-184. 